Research Article

\title{
Waterfowl Production From Winter Wheat Fields in North and South Dakota
}

\author{
BRANDI R. SKONE, ${ }^{\mathbf{1 , 2}}$ Department of Ecology, Montana State University, Bozeman, MT 59717, USA \\ JAY J. ROTELLA, Department of Ecology, Montana State University, Bozeman, MT 59717, USA \\ JOHANN WALKER, Great Plains Regional Office, Ducks Unlimited, 2525 River Road, Bismarck, ND 58503, USA
}

\begin{abstract}
The Prairie Pothole Region (PPR) of North America produces more than $50 \%$ of North America's upland-nesting ducks. With the recent increase in economic value of some cash-crops and the potential to lose productive nesting habitat enrolled in the Conservation Reserve Program (CRP), there has been interest in evaluating the efficacy of alternative farming practices to provide additional breeding habitat for waterfowl. We evaluated and compared daily survival rates (DSR) of duck nests (Anas spp.) in winter wheat with those in perennial cover. We also examined the number of hatched nests/ha in each habitat and compared them to estimates in spring wheat to put habitat-specific estimates of nest survival in perspective. We monitored 1,195 nests in winter wheat and 3,147 in perennial cover in North and South Dakota on $13-19,10.36-\mathrm{km}^{2}$ sites each year from 2010 to 2012. In 2010, we also monitored 75 nests in spring wheat. We used an information-theoretic approach to develop and evaluate a set of competing models based on plausible and previously established covariates affecting nest survival. Across all species, nest survival was at least as high in winter wheat as in perennial cover, and for northern pintails and mallards, estimated nest survival rates were greater in winter wheat. Nest survival also varied by year and study area, was positively related to nest age, and was negatively related to the number of wetland basins, the proportion of cropland in the landscape, and vegetation density. Density of hatched nests in perennial cover $(0.14 /$ ha) was on average twice as high as nests in winter wheat fields $(0.07 / \mathrm{ha})$, which was in turn 4 times higher than estimates for spring wheat fields $(0.02 / \mathrm{ha})$. Our results provide evidence that winter wheat could be a useful tool for wildlife managers seeking to add productive nesting habitat in landscapes under intensive crop production. (c) 2015 The Wildlife Society.
\end{abstract}

KEY WORDS agriculture, Anas spp., dabbling ducks, daily survival rate, nest success, North Dakota, Prairie Pothole Region, waterfowl, winter wheat.

The Prairie Pothole Region (PPR), which extends from the south-central portion of Canada including Alberta, Saskatchewan, and Manitoba, down to the north-central portion of the United States including Montana, North Dakota, South Dakota, Minnesota, and Iowa, is one of the most important areas for breeding ducks and has been established as a top priority for waterfowl conservation (U.S. Department of the Interior and Environment Canada 1986). This area is characterized by thousands of small wetlands (i.e., potholes) throughout the landscape as a result of glaciations over 10,000 years ago (van der Valk 1989). Although the PPR has value as a breeding ground for ducks, it is also valuable for agricultural production. Over the last century, there has been a shift in land use from native mixed

Received: 8 February 2015; Accepted: 26 August 2015

${ }^{1}$ E-mail: bskone@mt.gov

${ }^{2}$ Present Address: Montana Fish, Wildlife and Parks, PO Box 1630, Miles City, MT 59301, USA and tall grass prairie to agriculture in the form of cultivated crops, pastures, and rangeland (Dahl 1990). In the United States, an estimated 105 million ha of grassland were lost from 1850 to 1950 and more recently 11 million ha were lost between 1950 and 1997 (Claassen et al. 2011).

Hoekman et al. (2002) reported that nest success was one of the most important factors for population growth of mallards (Anas platyrhynchos) and presumably other upland nesting duck species (Pieron and Rohwer 2010). With ongoing loss of grasslands (Claassen et al. 2011), wildlife managers are always looking for methods to increase area of productive nesting cover. Programs like the Conservation Reserve Program (CRP) were initiated over 30 years ago to re-establish grassland habitat, protect air and water quality, reduce soil erosion caused by the intensification of agriculture, reduce crop surpluses, and increase commodity prices (Reynolds et al. 2001, U.S. Department of Agriculture Farm Service Agency 2013). The CRP offers landowners a monetary incentive to voluntarily take their fields out of production and establish perennial grass or tree cover for 1015 years. This program has been positively associated with 
nest success and recruitment rates of breeding ducks (Reynolds et al. 2001, Drever et al. 2007). However, the area enrolled in the program has significantly declined over the last 5 years; this negative trend is predicted to continue (U.S. Department of Agriculture Farm Service Agency 2013). With the growing prices for some cash crops and the push to produce biofuels, the economic incentive is greater to convert what is left of the native prairie or CRP to cropland (Claassen et al. 2011).

Although previous studies documented waterfowl nesting in cropland (Higgins 1977, Cowan 1982, Lokemoen and Beiser 1997), our knowledge of the importance of croplands to nesting ducks remains limited because of the difficulty of obtaining adequate sample sizes while avoiding crop destruction (Devries et al. 2008). The few studies that have been able to quantify nest success and apparent nest density have reported extremely low estimates for both in spring-seeded crops (Higgins 1977, Cowan 1982, Devries et al. 2008). Although predation is the predominant cause of nest failure for upland nesting ducks (Duebbert and Kantrud 1987, Sovada et al. 2001, Pieron and Rohwer 2010), nests initiated in spring-seeded cropland also face risks of destruction from farming processes including seeding, tillage, and spraying operations during a critical period of the nesting season (Devries et al. 2008).

Because fall-seeded crops are planted in the fall, remain dormant through the winter, and begin growing in the spring before ducks arrive to nest, they can provide attractive cover for early-nesting birds. Furthermore, nests in fall-seeded crops are not exposed to seeding and tillage operations during the spring. Devries et al. (2008) reported higher nest success and apparent nest density in winter wheat and fall rye when compared with spring-seeded crops in the parklands and grasslands of Saskatchewan. Other studies in Canada (Cowan 1982) and in the United States (Duebbert and Kantrud 1987) have reported similar results with no-till cropland. We were interested in evaluating the extent to which winter wheat, a fall-seeded crop, might serve as a suitable nesting habitat for breeding ducks in the PPR of the United States.

Our primary objective was to evaluate and compare daily survival rate (DSR) of nests in winter wheat to DSR of nests in perennial cover for the 5 most common upland nesting duck species: blue-winged teal (Anas discors), gadwall ( $A$. strepera), mallard, northern pintail (A. acuta), and northern shoveler (A. clypeata). Based on previous research (Duebbert and Kantrud 1987, Devries et al. 2008), we predicted that DSRs would be similar for nests in winter wheat and perennial cover. As a secondary objective, we also assessed the number of hatched nests/ha in winter wheat and perennial cover and compared them with numbers in spring wheat. We expected the number of hatched nests/ha to be lower in winter wheat than in perennial cover because of the characteristics associated with monoculture habitats. However, given the results of previous research in spring-seeded crops, we expected the number of hatched nests/ha to be lower overall in spring wheat.

\section{STUDY AREA}

We conducted our study from 2010 through 2012 in portions of the drift prairie and Missouri coteau physiographic regions of the PPR of North and South Dakota. In all 3 years, we had a study area near Minot, North Dakota (48 $13^{\prime} 59^{\prime \prime} \mathrm{N}, 101^{\circ}$ $17^{\prime} 32^{\prime \prime} \mathrm{W}$ ) in the northwest region (NWR) of the state. In 2011 only, we also included a study area in the south-central region (SCR) near Ashley, North Dakota $\left(46^{\circ} 2^{\prime} 6^{\prime \prime} \mathrm{N}, 99^{\circ}\right.$ $22^{\prime} 25^{\prime \prime} \mathrm{W}$ ). This study area was included to increase our scope of inference about winter wheat in landscapes of varying amounts of grassland and cropland. However, we were unable to solicit enough winter wheat producers the following year to warrant inclusion in the study.

Both regions were dominated by small grain, oil seed, pulse crops, and row-crop agriculture. Perennial cover included fragmented remains of mixed prairie, hay, pasture (grazed and ungrazed), idle cover enrolled in the CRP, or grassland patches alongside roadways (right-of-ways). Further details on topography, elevation, weather, and other dominant species within the study area (including mammalian predators), can be found in Stephens et al. (2005), Pieron and Rohwer (2010), and Walker et al. (2013).

\section{METHODS}

\section{Study Design}

We conducted our research on 13 sites in 2010 and 2011 and 19 sites in 2012. Each site was a $10.36-\mathrm{km}^{2}$ area (Stephens et al. 2005, Walker et al. 2013) that contained $\geq 1$ winter wheat field and 1 perennial cover field in all 3 years. In 2010, spring wheat was also included in a site. We categorized grassland, CRP, pasture, hayfields, and right-of-way as perennial cover. Initially, we attempted to randomly sample winter wheat fields in our study areas, but abandoned this method because of the unpredictability of where winter wheat would be planted each year. Instead, we canvassed producers and offered incentive payments to those who were known to have purchased winter wheat seed and sought permission to search for nests in their winter wheat fields.

Where permission was granted, we narrowed our selection to fields within a site that contained $\geq 50$ wetland basins, a number known to support breeding ducks at a level that facilitates successful nest sampling (Reynolds et al. 2006). Basins included wetlands that were wet or dry to account for permanent, semi-permanent, temporary, and seasonal wetlands. We then stratified sites by basin count as low (50165), medium (166-280), and high (281-430) within study areas. We sampled sites evenly from these categories and considered convenience of location if we had more than enough fields to choose from in each category.

Once we had a winter wheat field that met the sampling criteria, we located and gained permission on $\geq 1$ perennial cover field within $10.36 \mathrm{~km}^{2}$ of the center of the winter wheat field. In 2010, we also gained permission and offered compensation for $\geq 1$ spring wheat field within a site (10.36$\mathrm{km}^{2}$ area). In a few cases, we were unable to pair winter wheat with perennial cover within a site and had to use a field of perennial cover that was farther away but that had the 
appropriate number of wetland basins in the surrounding landscape.

The amount of area searched for each habitat varied by year but totaled 7,670 ha in winter wheat, 10,114 ha in perennial cover, and 2,154 ha in spring wheat. Because of financial limitations and the limited sample of nests, we were able to find in spring wheat, which was consistent with reports from other studies in spring-seeded crops (Higgins 1977, Greenwood et al. 1995, Devries et al. 2008), we only collected data from spring wheat in 2010. In 2011, extremely wet spring weather conflicted with the restriction that we could only search winter wheat in relatively dry-soil conditions to avoid damaging crops. As a consequence, the area searched in winter wheat was less than the area searched in perennial cover.

\section{Field Methods}

We systematically searched sites up to 4 times from late April to mid July at approximately 3-4-week intervals using the drag method described by Klett et al. (1986). We dragged a nylon rope between 2 all-terrain vehicles to flush nesting females, get a visual mark on where the female flushed, and locate the nests. We used a nylon rope rather than a chain to minimize damage to wheat (Devries et al. 2008). We conducted searches between 0700 and $1400 \mathrm{hr}$ to maximize the probability that females were attending nests (Gloutney et al. 1993). Once we found a nest, we determined and recorded the nesting species, number of eggs, nest age, date, vegetation density, geographic coordinates, and status of the nest.

We determined the species based on visual features of the female that flushed from the nest or by examining feathers found in the nest bowl (Klett et al. 1986). We recorded visual obstruction readings (VORs) to the nearest $5 \mathrm{~cm}$ in 4 cardinal directions, $4 \mathrm{~m}$ from the nest at a height of $1 \mathrm{~m}$ (Robel et al. 1970) and estimated nest-site vegetation density by averaging the 4 measurements. We recorded the geographic coordinates using a handheld global positioning system unit and marked the nest with a 1-m fiberglass pole and pink flagging, $4 \mathrm{~m}$ north of the nest to make relocation easier.

We continued to monitor nests every 7-10 days until eggs hatched or the nest was destroyed or abandoned. We determined a successful nest to be one that hatched $\geq 1$ egg. We considered nests destroyed or abandoned failed nests and excluded from analysis any nest considered abandoned because of investigator influence. Nest searching protocols were approved under scientific collector's permits through the North Dakota Game and Fish Department (GNF02937916 and GNF03127342 in 2011 and 2012, respectively) and the South Dakota Department of Game, Fish, and Parks (43).

\section{Covariates of Interest and Hypotheses}

We developed a list of covariates at varying nest and landscape scales for use in competing models of daily nest survival based on our research questions and what has been reported as important in the literature on waterfowl nest survival. We included habitat in the list to allow us to evaluate a possible difference in survival rates for nests in winter wheat (WW) versus perennial cover (PC). We included species to account for expected variation, and predicted higher nest survival for blue-winged teal, gadwall, and northern shovelers than for mallards and northern pintails (Klett et al. 1988, Beauchamp et al. 1996, Pieron and Rohwer 2010). We included study area (NWR and SCR) and year (2010, 2011, and 2012) as categorical predictor variables that might explain potential temporal and spatial variation in nest survival (Dinsmore et al. 2002).

We examined several continuous covariates that were expected to explain variation in nest survival. We expected nest survival to increase with nest age (Stephens et al. 2005, Grant and Shaffer 2012, Walker et al. 2013) because of modified female activity at the nest as the season progressed (Forbes et al. 1994), and because nests at higher risk tended to fail at younger ages (Klett and Johnson 1982). We included initiation date and calendar date to account for possible seasonal variation in nest survival rates. We standardized calendar dates among years by using the earliest date a nest was found for any year as the first day of the season.

We calculated the number of wetland basins and proportion of cropland (including winter wheat) in the landscape around the nest $\left(10.36 \mathrm{~km}^{2}\right.$ and $41.4 \mathrm{~km}^{2}$, respectively) using ArcGIS 10.1 (Environmental Systems Research Institute, Inc., Redlands, CA) and satellite imagery layers from the National Wetlands Inventory (NWI), and the United States Department of Agriculture National Agricultural Statistics Service (USDA NASS), respectively. We predicted a negative relationship between nest survival and the number of wetland basins at the site level (Stephens et al. 2005). Given that some duck-nest predators prefer wetlands and wetland edges (Larivière and Messier 2000, Kuehl and Clark 2002, Phillips et al. 2003), we expected an increase in the number of wetlands in the landscape would expose more duck nests to predators. We also expected the proportion of cropland in a $41.4-\mathrm{km}^{2}$ area including and surrounding a site (Stephens et al. 2005) to be negatively related to nest survival (Reynolds et al. 2001, Drever et al. 2007, Bloom et al. 2013). The conversion of grassland to cropland often results in fragmented patches in the landscape (Gehring and Swihart 2003) and a decrease in grassland patch size (Saunders et al. 1991). Foraging patterns of nest predators are affected by fragmentation and foraging efficiency of predators is higher in smaller patches of grassland such that nest survival in smaller patches is lower (Sovada et al. 2000, Phillips et al. 2003, Stephens et al. 2005).

We expected vegetation density at the nest to have a positive relationship with nest survival (Warren et al. 2008, Thompson et al. 2012, Bloom et al. 2013). We predicted that more dense vegetation would decrease foraging efficiency of predators, conceal nests better, and have a positive effect on nest survival (Sugden and Beyersbergen 1987, Stephens et al. 2005).

\section{Modeling of Daily Nest Survival}

We used an information-theoretic approach (Burnham and Anderson 2002) and developed a set of candidate models 
based on our covariates. We ran all possible linear additive combinations of the covariates (Doherty et al. 2010) but held species constant within all models as a baseline covariate to account for expected variation (Stephens et al. 2005, Walker et al. 2013). We included an intercept-only (null) model for comparison. To explore possible interactions and potential nonlinearities that have been reported by previous work, we included interaction terms between species and habitat (Klett and Johnson 1982, Stephens et al. 2005, Walker et al. 2013), species and nest age (Grant and Shaffer 2012), and a quadratic term for nest age (Grant et al. 2005, Pieron and Rohwer 2010, Grant and Shaffer 2012). We also checked for collinearity between covariates by assessing correlation coefficients before proceeding to model the data. Correlation coefficients ranged from 0.01 to 0.29 , providing evidence that collinearity was low.

We used the nest survival module (Dinsmore et al. 2002) in Program MARK (White and Burnham 1999) through the RMark package (Laake 2013) in Program R (R Development Core Team 2013) to model DSR as a function of nest and landscape-scale covariates. Specifically, we used a logit link with a binomial error distribution to model DSR with:

$\mathrm{DSR}_{j i}=\frac{{ }^{\beta_{0}}+\sum_{j}^{\beta_{j} x_{j i}}}{{ }_{1+\exp }^{\beta_{0}}+\sum_{j}{ }_{j} x_{j i}}$. Here, $\operatorname{DSR}_{j i}$ is the daily survival rate for the $j$ th covariate on the $i$ th day, $\beta_{0}$ is the intercept, $\beta_{j}$ is the estimated coefficient for the $j$ covariate, and $\chi_{j i}$ is the value for the $j$ covariate on day $i$ (Rotella et al. 2004).

This method assumes that 1 ) nests are accurately aged when found, 2) nest fates are assigned correctly, 3) finding and monitoring a nest does not influence its fate, 4) nest fates are independent of one another, and 5) no heterogeneity exists among DSR as modeled (Dinsmore et al. 2002). For assumption 1, we candled the eggs to determine the incubation stage (Weller 1956) when the nest was found and on each return visit to confirm incubation was progressing and the nest was accurately aged. For the second assumption, evidence to discriminate between hatched and failed nests was discrete (Klett et al. 1986), and we excluded nests for which fate was uncertain from the analysis. For the third assumption, we minimized the amount of time $(<5 \mathrm{~min})$ and disturbance at the nest when found and on later visits. For the fourth assumption, we tested for overdispersion $(\hat{c})$ by bootstrapping our data at the field level (Bishop et al. 2008). We ran over 1,000 simulations directly in Program MARK using a highly parameterized model. We calculated estimates and standard error of DSR based on estimated coefficients for each simulated data set for nests aged 5-35 days (ages of nests that were common in our data). We held all other covariates at their mean values. We calculated the standard deviation of the estimates for each nest age. We then calculated the average standard error for DSR for each nest age and used the following equation to estimate $\hat{c}$ for each age: $\hat{c}=\frac{\mathrm{SD}^{2}}{\overline{\mathrm{SE}}^{2}}$. We obtained our final estimate of $\hat{c}$ by averaging the age-specific $\hat{c}$ estimates. For the fifth assumption, we attempted to adequately model the heterogeneity in our data with diverse covariates but, to our knowledge, there is no goodness-of-fit test available that is unbiased and practical given the size of our dataset (Sturdivant et al. 2007, Walker et al. 2013).

We used Akaike's Information Criterion with a correction for small sample size $\left(\mathrm{AIC}_{c}\right)$ to rank our models and assess which were most important for evaluating DSR (Burnham and Anderson 2002). We also adjusted $\mathrm{AIC}_{c}$ scores and variances for estimated overdispersion $\left(\hat{c}=1.32\right.$; $\left.\mathrm{QAIC}_{c}\right)$. We used the $\mathrm{QAIC}_{c}$ value associated with each model to rank and assess importance by considering the $\Delta \mathrm{QAIC}_{c}$ value and $\mathrm{QAIC}_{c}$ weight $\left(\omega_{\mathrm{i}}\right)$ associated with each model. We calculated $\Delta \mathrm{QAIC}_{c}$ by subtracting the $\mathrm{QAIC}_{c}$ value of the model with the lowest score from the respective model's $\mathrm{QAIC}_{c}$ value being assessed. We considered models that were $\leq 2 \Delta \mathrm{QAIC}_{c}$ units of the top model strongly supported by the data and models $\leq 7 \Delta \mathrm{QAIC}_{c}$ units away moderately supported by the data (Burnham and Anderson 2002). We also assessed the importance of covariates within strongly and moderately supported models by evaluating $95 \%$ confidence intervals for estimated coefficients and the extent to which they might have overlapped 0 . We used a 35-day incubation period for mallards and gadwalls, 34 days for blue-winged teal and northern shovelers, and 32 days for northern pintails when converting estimates of DSR to point estimates of nest success (Klett et al. 1986). We calculated nest success (NS) estimates for each categorical variable (i.e., species, habitat, year, and study area) from our top model, across all nest ages $\left(\mathrm{NS}=\mathrm{DSR}_{\mathrm{Age} 1} \times \mathrm{DSR}_{\mathrm{Age} 2} \times \mathrm{DSR}_{\mathrm{Age} 3} \times \ldots \mathrm{DSR}_{\mathrm{AgeMax}}\right)$ while holding all continuous variables (i.e., wetland basin count, proportion of cropland, and vegetation density) at their mean values, unless otherwise stated. We used the delta method to calculate standard errors (Powell 2007).

\section{Density of Hatched Nests}

We calculated the number of hatched nests/ha in each habitat and year to put habitat-specific estimates of DSR in perspective. We did not calculate nest abundance because the number of nests initiated and failed between searches is unknown (Devries et al. 2008) and because some nests go undetected with the search methods we used (Higgins et al. 1977, Gloutney et al. 1993). However, a recent study indicated that repeated nest searching misses few successful nests (Péron et al. 2014). Consequently, we used sites that were searched $\geq 3$ times consistently throughout the season to assess hatched nest density.

For each habitat, we determined the number of successful nests ( $\geq 1$ egg hatched) and divided by the area searched to calculate hatched nests/ha. We included data collected in 2010 from spring wheat fields to provide perspective on how the number of hatched nests/ha in winter wheat fields compare to values in spring-seeded crops.

\section{RESULTS}

We found and monitored 1,195 nests in winter wheat, 3,147 nests in perennial cover, and 75 nests in spring wheat of 8 duck species. Our sampling covered most of the nesting season across all 3 habitats. This resulted in 50,422 exposure 
days used to estimate DSR. The number of nests varied among habitats, species, and years (Table 1). The most common nesting species were mallards (24\%), northern pintails (23\%), and gadwalls (22\%) for winter wheat, bluewinged teal (36\%), mallards (20\%), and gadwalls (19\%) for perennial cover, and northern pintails (39\%), blue-winged teal (29\%), and mallards (19\%) for spring wheat (Table 1). We also found a few lesser scaup (Aythya affinis), and American wigeon (Anas americana) nests in all 3 habitats, and green-winged teal (Anas crecca) nests in winter wheat and perennial cover (Table 1).

We monitored nests on sites that varied widely in terms of their values for basin count and proportion of cropland. The number of basins ranged from 58 to 427 by site with an average of $204(\mathrm{SD}=66.76)$. Proportion of cropland by site ranged from 0.08 to 0.89 with an average of 0.51 $(\mathrm{SD}=0.18)$. Nest vegetation density ranged from VOR values of 0 to $11.13 \mathrm{dm}$ with an average of $4.22(\mathrm{SD}=2.24)$ in winter wheat fields, and 0 to $12.63 \mathrm{dm}$ with an average of $3.11(\mathrm{SD}=1.38)$ in perennial cover fields.

\section{Nest Survival}

Model structures were similar among well-supported models, and the relationship between any given covariate and DSR was consistent across those models. All models that were within $7 \Delta$ QAIC $_{c}$ units of the top model included species (contained in all models by design), habitat, year, nest age, and wetland basin count. In addition to the covariates supported in all models, we also found support from models within $2 \mathrm{QAIC}_{c}$ units of the top model (Table 2) for including 1) an interaction between species and habitat (12 of 15 models), 2) study area (10 of 15 models), 3) nest vegetation density (9 of 15 models), 4) cropland (8 of 15 models), 5) calendar date (3 of 15 models), and 6) a quadratic term for nest age ( 2 of 15 models). However, estimated coefficients for covariates that were included in approximately half of the models had associated $95 \%$ confidence intervals that overlapped 0 , preventing us from making strong inferences about their importance. Relationships between nest DSR and covariates were consistent in all the well-supported models and all covariates in moderately and highly supported models were included in our top model. Thus, we focus on results from our top model.

Table 1. Species composition of nests by habitat at study sites in North and South Dakota, USA, 2010-2012. Habitats included perennial cover $(\mathrm{PC})$, winter wheat (WW), and spring wheat (SW). We only collected data from spring wheat in 2010 .

\begin{tabular}{|c|c|c|c|c|c|c|c|}
\hline \multirow[b]{2}{*}{ Species } & \multicolumn{3}{|c|}{2010} & \multicolumn{2}{|c|}{2011} & \multicolumn{2}{|c|}{2012} \\
\hline & PC & WW & SW & PC & WW & PC & WW \\
\hline Blue-winged teal & 310 & 108 & 22 & 445 & 28 & 364 & 78 \\
\hline Gadwall & 146 & 104 & 3 & 141 & 28 & 317 & 126 \\
\hline Mallard & 184 & 121 & 14 & 183 & 56 & 261 & 104 \\
\hline Northern pintail & 61 & 122 & 29 & 136 & 39 & 118 & 113 \\
\hline Northern shoveler & 155 & 94 & 4 & 124 & 20 & 96 & 29 \\
\hline Lesser scaup & 11 & 4 & 2 & 11 & 3 & 41 & 4 \\
\hline American wigeon & 15 & 7 & 1 & 0 & 1 & 15 & 4 \\
\hline Green-winged teal & 2 & 1 & 0 & 7 & 0 & 4 & 1 \\
\hline Total & 884 & 561 & 75 & 1,047 & 175 & 1,216 & 459 \\
\hline
\end{tabular}

Although the strength of the relationship between habitat and nest survival varied by species, no species had a point estimate for DSR in winter wheat below that for perennial cover. The strongest difference was for northern pintails $\left(\hat{\beta}_{\mathrm{NOPI} \times \mathrm{WW}}=0.427, \mathrm{SE}=0.184 ;\right.$ Fig. 1$)$, with an estimated DSR in 2012 of $0.95(95 \% \mathrm{CI}=0.92-0.96)$ in winter wheat compared to $0.91(95 \% \mathrm{CI}=0.88-0.94)$ in perennial cover. This equated to a 32-day nest success rate in 2012 of $36 \%(\mathrm{SE}=4.18)$ in winter wheat and $19 \%(\mathrm{SE}=2.89)$ in perennial cover. There was also some evidence that mallards had higher nest survival in winter wheat than in perennial cover $\left(\hat{\beta}_{\mathrm{MALL} \times \mathrm{WW}}=0.252, \mathrm{SE}=0.165\right.$; Fig. 1$)$, with an estimated DSR in 2012 of $0.94(95 \% \mathrm{CI}=0.92-0.96)$ in winter wheat compared to $0.92(95 \% \mathrm{CI}=0.89-0.94)$ in perennial cover. This equated to a 35 -day nest success rate in 2012 of $29 \%(\mathrm{SE}=3.89)$ in winter wheat and $18 \%$ $(\mathrm{SE}=2.09)$ in perennial cover. For other species, differences were less clear (Fig. 1).

The DSR varied by year and was estimated to be highest in $2012\left(\hat{\beta}_{2012}=0.117, \mathrm{SE}=0.063\right)$ and lowest in 2011 $\left(\hat{\beta}_{2011}=-0.225, \mathrm{SE}=0.080 ;\right.$ Fig. 1$)$. Nest age, as predicted, was positively associated with DSR $\left(\hat{\beta}_{\text {NestAge }}=0.011\right.$, $\mathrm{SE}=0.003)$. We also found evidence that DSR was higher on the NWR study area $\left(\hat{\beta}_{\mathrm{NWR}}=0.144, \mathrm{SE}=0.088\right)$.

We investigated whether relationships between nest survival and the continuous habitat covariates (i.e., wetland basins, proportion of cropland, and vegetation density) varied between nests in perennial cover and those in winter wheat. The data provided stronger support for the simpler model, and had $95 \%$ confidence intervals that overlapped 0 . Thus, we made inferences about the main effects of our continuous covariates for nests in both habitat types. As expected, DSR was negatively related to the number of wetland basins $\left(\hat{\beta}_{\text {Basin }}=-0.002, \mathrm{SE}<0.001 ;\right.$ Fig. 2$)$ and to the proportion of cropland on the landscape $\left(\hat{\beta}_{\text {Crop }}=-0.264, \mathrm{SE}=0.174\right.$; Fig. 3). Contrary to our prediction, DSR was lower for nest sites with higher vegetation density $\left(\hat{\beta}_{\mathrm{VOR}}=-0.031\right.$, $\mathrm{SE}=0.018)$.

\section{Density of Hatched Nests}

Sites that we searched $\geq 3$ times each year from 2010 to 2012 summed to 5,265 ha in perennial cover and 4,357 ha in winter wheat, and in 2010 only we searched sites totaling 1,105 ha of spring wheat. The area searched varied by year but was consistent in perennial cover and winter wheat, with the exception of 2011 (Table 3). Because of the extreme wet conditions of 2011, we were unable to search most of our sites $\geq 3$ times during the nesting season. Hatched nests/ha ranged from 0.016 to 0.103 in winter wheat, 0.120 to 0.153 in perennial cover, and 0.019 in spring wheat (Table 3).

\section{DISCUSSION}

\section{Nest Survival Relationships With Habitat}

We provided supporting evidence of all 5 common uplandnesting ducks nesting in winter wheat within the PPR of North and South Dakota. Our nest survival estimates for winter wheat were slightly lower than those reported by previous studies (Duebbert and Kantrud 1987, Devries et al. 
Table 2. Models strongly supported (i.e., within 2 Akaike's Information Criterion corrected for small sample size and overdispersion [QAIC $c$ ] units of the top-ranked model) for duck nest survival in North and South Dakota, 2010-2012. Covariates are species (spp*), habitat (hab*), year*, study area (study), nest age*, wetland basin count (basin*), proportion of cropland (crop), vegetation density (VOR), and calendar date (date). All the models presented in the table also include main effects of the covariates with an asterisk (above) with the exception of the null model, which is included for comparison. $K$ is the number of parameters in the model.

\begin{tabular}{|c|c|c|c|c|c|}
\hline Model & $\mathrm{QAIC}_{c}$ & $\Delta \mathrm{QAIC}_{c}$ & QAIC $_{c}$ weights & Model likelihood & $K$ \\
\hline $\mathrm{Spp} \times$ hab + study + crop $+\mathrm{VOR}^{\mathrm{a}}$ & $8,211.84$ & 0.00 & 0.05 & 1.00 & 17 \\
\hline Spp $\times$ hab+study+VOR & $8,212.15$ & 0.31 & 0.04 & 0.85 & 16 \\
\hline Spp $\times$ hab + crop + VOR & $8,212.51$ & 0.67 & 0.04 & 0.72 & 16 \\
\hline Spp $\times$ hab + study & $8,212.51$ & 0.67 & 0.04 & 0.71 & 15 \\
\hline Spp $\times$ hab + study + crop & $8,212.58$ & 0.75 & 0.03 & 0.69 & 16 \\
\hline Study+crop+VOR & $8,212.76$ & 0.92 & 0.03 & 0.63 & 13 \\
\hline Spp $\times$ hab + VOR & $8,212.86$ & 1.02 & 0.03 & 0.60 & 15 \\
\hline Study+VOR & $8,213.14$ & 1.30 & 0.03 & 0.52 & 12 \\
\hline Spp $\times$ hab + study + crop + VOR + nest age $^{2}$ & $8,213.20$ & 1.37 & 0.02 & 0.50 & 18 \\
\hline Spp $\times$ hab + study + crop + date & $8,213.30$ & 1.46 & 0.02 & 0.48 & 17 \\
\hline Spp $\times$ hab + study + date & $8,213.31$ & 1.47 & 0.02 & 0.48 & 16 \\
\hline Spp $\times$ hab & $8,213.37$ & 1.53 & 0.02 & 0.47 & 14 \\
\hline Spp $\times$ hab + crop & $8,213.42$ & 1.58 & 0.02 & 0.45 & 15 \\
\hline Crop+VOR & $8,213.50$ & 1.66 & 0.02 & 0.44 & 12 \\
\hline $\mathrm{Spp} \times$ hab + study $+\mathrm{VOR}+$ nest age $^{2}$ & $8,213.53$ & 1.69 & 0.02 & 0.43 & 17 \\
\hline $\mathrm{Spp} \times \mathrm{hab}+$ study + crop + VOR + date & $8,213.61$ & 1.77 & 0.02 & 0.41 & 18 \\
\hline Null & $8,335.73$ & 123.89 & 0.00 & 0.00 & 1 \\
\hline
\end{tabular}

${ }^{\mathrm{a}}$ Top model $\hat{\beta}_{\mathrm{S}}$ are as follows: $\hat{\beta}_{\text {Intercept }}=3.617(\mathrm{SE}=0.178), \hat{\beta}_{\mathrm{WW}}=0.088(\mathrm{SE}=0.125), \hat{\beta}_{\mathrm{GADW}}=0.011(\mathrm{SE}=0.087), \hat{\beta}_{\mathrm{MALL}}=-0.344(\mathrm{SE}=0.080)$, $\hat{\beta}_{\mathrm{NOPI}}=-0.395(\mathrm{SE}=0.098), \hat{\beta}_{\mathrm{NSHO}}=-0.244(\mathrm{SE}=0.091), \hat{\beta}_{\mathrm{GADW} \times \mathrm{WW}}=-0.043(\mathrm{SE}=0.170), \hat{\beta}_{\mathrm{MALL} \times \mathrm{WW}}=0.252(\mathrm{SE}=0.165), \hat{\beta}_{\mathrm{NOPI} \times \mathrm{WW}}=$ $0.427(\mathrm{SE}=0.184), \hat{\beta}_{\mathrm{NSHO}} \times \mathrm{WW}=0.125(\mathrm{SE}=0.194), \hat{\beta}_{2011}=-0.225 \quad(\mathrm{SE}=0.080), \hat{\beta}_{2012}=0.117 \quad(\mathrm{SE}=0.063), \hat{\beta}_{\text {Nestage }}=0.011 \quad(\mathrm{SE}=0.003)$, $\hat{\beta}_{\mathrm{NWR}}=0.144(\mathrm{SE}=0.088), \hat{\beta}_{\text {Basin }}=-0.002(\mathrm{SE}<0.001), \hat{\beta}_{\text {Crop }}=-0.264(\mathrm{SE}=0.174), \hat{\beta}_{\mathrm{VOR}}=-0.031(\mathrm{SE}=0.018)$. For habitat, WW represents winter wheat. Species include gadwall (GADW), mallard (MALL), northern pintail (NOPI), and northern shoveler (NSHO). For study area, NWR represents the northwest study area.
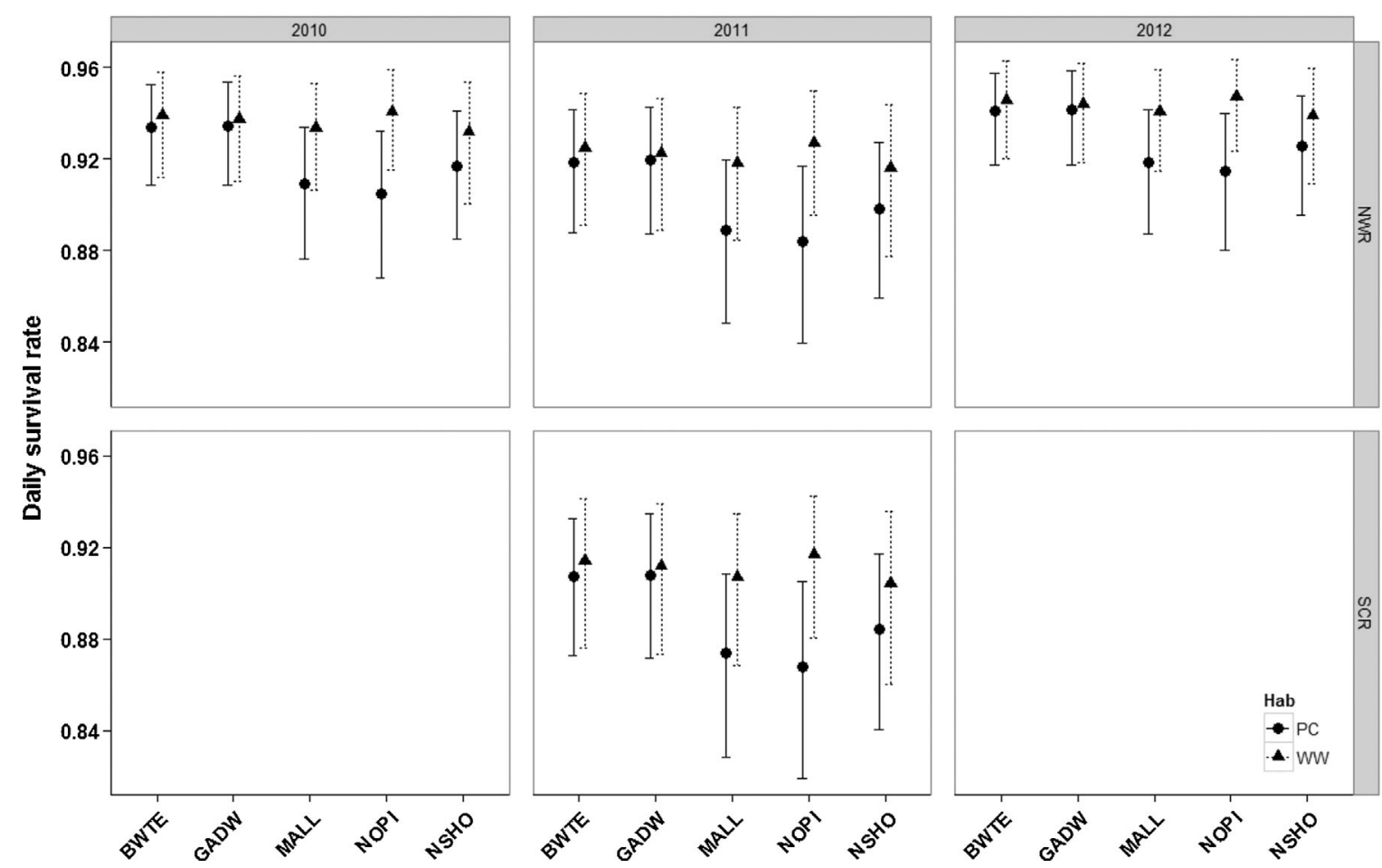

Figure 1. Daily nest survival rates by species and year in winter wheat (WW) and perennial cover (PC) of the northwest region (NWR) and south central region (SCR) study areas, North and South Dakota, USA, 2010-2012. Error bars represent 95\% confidence intervals associated with point estimates. Wetland basin count, nest age, proportion of cropland, and vegetation density were held at their mean values. Species included blue-winged teal (BWTE), gadwall (GADW), mallard (MALL), northern pintail (NOPI), and northern shoveler (NSHO). 


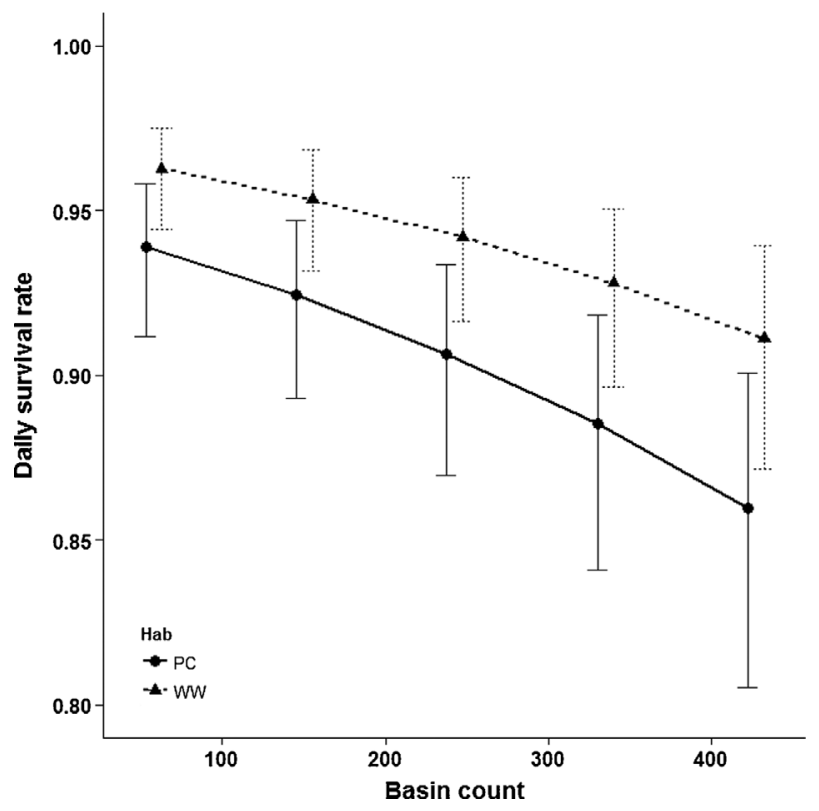

Figure 2. Daily survival rate of northern pintail nests in winter wheat (WW) and perennial cover (PC) in relation to the number of wetland basins in the landscape at the $10.4-\mathrm{km}^{2}$ scale in the northwest region study area, North Dakota, USA, 2012. Relationship between daily survival rate and wetland basin count were similar for other duck species, years, and study area. Error bars represent 95\% confidence intervals associated with point estimates. Continuous covariates (nest age, proportion of cropland, and vegetation density) were held at their mean values.

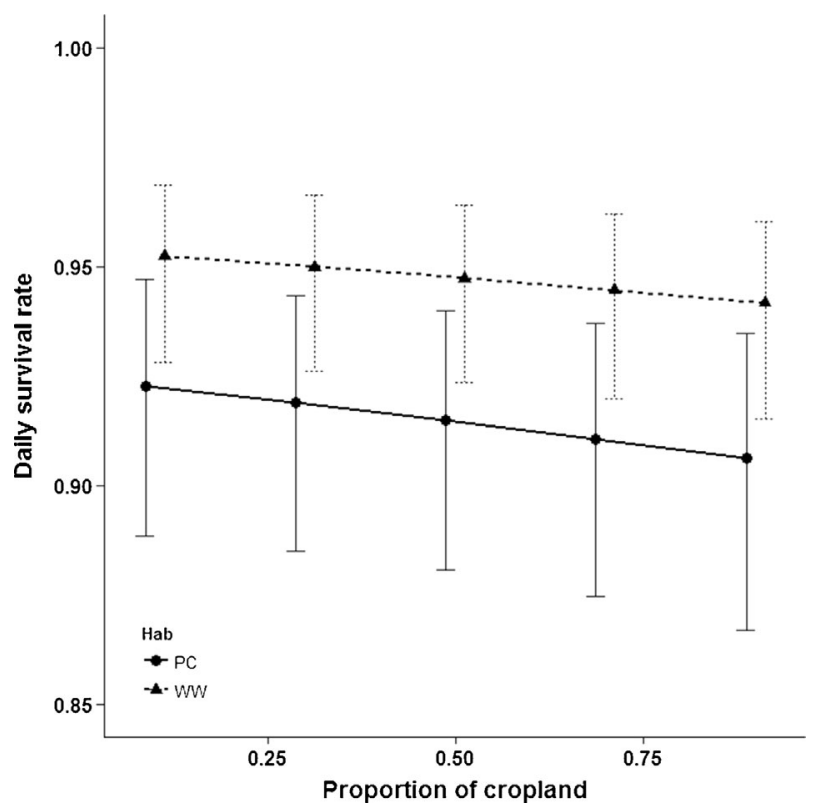

Figure 3. Daily survival rate of northern pintail nests in winter wheat (WW) and perennial cover (PC) in relation to the proportion of cropland in the landscape at the 41.4- $\mathrm{km}^{2}$ scale of the northwest study area, North Dakota, USA, 2012. Relationship between daily survival rate and proportion of cropland were similar for other duck species, years, and study area. Error bars represent $95 \%$ confidence intervals associated with point estimates. Continuous covariates (nest age, wetland basin count, and vegetation density) were held at their mean values.
2008), but our estimates for perennial cover were comparable to recent studies carried out in a similar area of the PPR of North Dakota (Stephens et al. 2005, Walker et al. 2013). To our knowledge, ours is the only study to explicitly compare survival rates for nests in winter wheat with those in perennial cover. We also provided evidence that nest survival was at least as high in winter wheat as in perennial cover, and for northern pintails and mallards, the survival rate was higher in winter wheat.

We propose several possible reasons for why nest survival was higher for some species in winter wheat than in perennial cover. First, previous work reported predation to be the most frequent cause of nest loss for waterfowl (Sargeant and Raveling 1992, Sovada et al. 2001, Pieron and Rohwer 2010), and evidence at the nests suggested this was also the case for both habitats in our study. However, we suspect the pressures from the predator communities within each habitat might be different. Mammals are the main predators of waterfowl nests in the PPR (Sargeant and Raveling 1992, Sargeant et al. 1993), but waterfowl nests are not the main component of most mammalian predator's diets (Sargeant et al. 1986, Greenwood et al. 1999, Sovada et al. 1999). Most duck-nest predators are generalists and consume anything from arthropods and other insects to small mammals and birds. Monocultures of winter wheat might be less attractive to foraging predators because of lower diversity and abundance of potential prey, such as small mammals and insects (Flowerdew 1997, Benton et al. 2003, Heroldová et al. 2007). Further, although we accounted for the number of wetland basins within a site $\left(10.36-\mathrm{km}^{2}\right.$ area), wetland density might be less within winter wheat fields because of agricultural practices like draining. If so, such sites might attract fewer mammalian predators, given that mammals prefer wetland edges and wet meadows that contain many prey species (Greenwood et al. 1999, Larivière and Messier 2000, Phillips et al. 2004).

Second, given our evidence that nest density was lower in winter wheat, it is also possible that density-dependent predation rates could partly be responsible for differences in habitat-specific nest survival rates. However, much uncertainty surrounds the topic of density-dependent predation for waterfowl nests (Major and Kendal 1996, Ackerman 2002). Some studies have reported strong evidence (Sugden and Beyersbergen 1986, Gunnarsson and Elmberg 2008), whereas others have reported no evidence (Ackerman et al. 2004, Padyšáková et al. 2010, Ringelman et al. 2012).

\section{Nest Survival Relationships With Species}

Consistent with previous literature (Stephens et al. 2005, Walker et al. 2013) and our expectation, we found evidence that nest survival rate varied by species to some extent. In perennial cover, we found mallards and northern pintails to have the lowest nest survival estimates and gadwall and bluewinged teal to have the highest estimates. On the contrary, in winter wheat we found northern pintails and mallards to have the highest nest survival estimates and gadwall and blue-winged teal to have the lowest estimates. Differences in nest survival rates between winter wheat and perennial cover 
Table 3. Number of hatched duck nests/ha in each habitat and year from sites sampled in North and South Dakota, 2010-2012. Only fields that were searched $\geq 3$ times each year were included in the area searched (area). Habitats included perennial cover (PC), winter wheat (WW), and spring wheat (SW).

\begin{tabular}{|c|c|c|c|c|c|c|c|c|c|}
\hline \multirow[b]{2}{*}{ Habitat } & \multicolumn{3}{|c|}{2010} & \multicolumn{3}{|c|}{2011} & \multicolumn{3}{|c|}{2012} \\
\hline & $\begin{array}{c}\text { Hatched } \\
\text { nests }\end{array}$ & $\begin{array}{c}\text { Area } \\
\text { (ha) }\end{array}$ & $\begin{array}{l}\text { Hatched } \\
\text { nests/ha }\end{array}$ & $\begin{array}{c}\text { Hatched } \\
\text { nests }\end{array}$ & $\begin{array}{c}\text { Area } \\
\text { (ha) }\end{array}$ & $\begin{array}{l}\text { Hatched } \\
\text { nests/ha }\end{array}$ & $\begin{array}{c}\text { Hatched } \\
\text { nests }\end{array}$ & $\begin{array}{c}\text { Area } \\
\text { (ha) }\end{array}$ & $\begin{array}{l}\text { Hatched } \\
\text { nests/ha }\end{array}$ \\
\hline PC & 290 & 2,324 & 0.125 & 82 & 686 & 0.120 & 346 & 2,255 & 0.153 \\
\hline WW & 133 & 2,376 & 0.056 & 4 & 248 & 0.016 & 179 & 1,733 & 0.103 \\
\hline SW & 21 & 1,105 & 0.019 & & & & & & \\
\hline
\end{tabular}

depended on species, with the most noticeable difference in estimates for northern pintails. Nests of northern pintails in winter wheat were about 2.4 times more likely to succeed than those in perennial cover. Nest success estimates across year and study area ranged from $7 \%(\mathrm{SE}=1.91)$ to $19 \%$ $(\mathrm{SE}=2.89)$ in perennial cover and were similar to estimates reported by Guyn and Clark (2000). Conversely, our estimates of nest success in winter wheat were substantially higher, ranging from $19 \%(\mathrm{SE}=4.06)$ to $36 \%(\mathrm{SE}=4.18)$. Northern pintails typically have low nest success (Klett et al. 1988) and prefer cropland habitat (Higgins 1977, Greenwood et al. 1995), where reported nest success estimates have been extremely low in spring-seeded crops (Milonski 1958, Klett et al. 1988, Greenwood et al. 1995). Winter wheat offers a potential management tool for this species that could be valuable given that northern pintail populations, unlike other populations of upland-nesting ducks, have not recovered since the sharp decline in all duck populations in the 1980s.

Mallard nests were also more likely to succeed in winter wheat than in perennial cover. However, for other species, nest survival in winter wheat was only as good as that in perennial cover. It is unclear why nest survival was higher in winter wheat for some species and comparable to that in perennial cover for others. Our estimates of nest success for all species in winter wheat were almost always greater than the recommended nest success rates required to maintain populations $(15 \%$ for northern pintails and mallards, Cowardin et al. 1985; 20\% for all other species, Klett et al. 1988).

\section{Nest Survival Relationships With Temporal and Spatial Characteristics}

Temporal and spatial variation has been documented widely in duck-nest survival studies throughout the PPR and was also evident in our study. As predicted and consistent with results of earlier studies (Stephens et al. 2005, Grant and Shaffer 2012, Thompson et al. 2012), we found that nest survival increased with nest age. However, we are unsure of the underlying mechanism. It could be the result of modified female behavior at the nest, such that females increase the amount of time spent at the nest (Caldwell and Cornwell 1975, Afton 1979, Klett and Johnson 1982) and allow predators to approach more closely as incubation progresses (Mallory and Weatherhead 1993, Forbes et al. 1994). The prolonged presence of the female at the nest could decrease the number of visual cues that might attract predators or be a physical deterrent for some predators (Thompson and
Raveling 1987, Ringelman and Stupaczuk 2013). However, it is also possible that the pattern seen was due to heterogeneity in nest survival whereby nests of lower quality tend to fail at higher rates early (Cam et al. 2002).

Consistent with our prediction and results of previous studies (Stephens et al. 2005, Thompson et al. 2012), we found that nest survival decreased with the number of wetland basins in the landscape. Although ducks prefer nesting in areas of greater wetland density (Cowardin et al. 1995, Krapu et al. 1997, Bloom et al. 2013), wetlands are associated with high levels of primary productivity (van der Valk 1989) that might help support predators in surrounding areas. Furthermore, some duck-nest predators prefer wetlands and wetland edges when foraging (Larivière and Messier 2000, Kuehl and Clark 2002, Phillips et al. 2004), and nests on sites with high wetland density can be expected to be closer to wetlands and more vulnerable to predators, on average, than they would be on drier sites.

We also found evidence that nest survival was negatively related to the proportion of cropland on the landscape. A few studies have reported no relationship between nest survival and cropland (Howerter 2003, Arnold et al. 2007, Walker et al. 2013), but numerous studies have found a negative pattern (Drever et al. 2007, Devries and Armstrong 2011, Bloom et al. 2013), which is in accordance with our results. The conversion of grassland to cropland has been associated with habitat fragmentation (Gehring and Swihart 2003), which likely affects foraging patterns of predators (Stephens et al. 2005). Some duck-nest predators reach their highest densities in highly fragmented landscapes (Donovan et al. 1997), and smaller patches of habitat have a positive effect on foraging efficiency of predators (Sovada et al. 2000, Phillips et al. 2003). Differences in abundance and distribution of alternative prey or the types of predator communities associated with different levels of cropland are not something we addressed with this study but could also play a role in the pattern we see with cropland.

Contrary to our prediction and evidence from previous studies (Warren et al. 2008, Thompson et al. 2012, Bloom et al. 2013), we found some evidence of a negative relationship between vegetation density at nest sites and nest survival. Although this was unexpected, the magnitude of the relationship was modest and numerous studies have not found evidence for a relationship between nest survival and vegetation density (Koons and Rotella 2003, Jimenez et al. 2007, Walker et al. 2008). We expected more dense vegetation to decrease predator foraging efficiency (Sugden and Beyersbergen 1987), but it is possible that nest-predation 
rates are higher in dense cover because both nesting females and predators are attracted to patches of dense vegetation (Jimenez et al. 2007).

\section{Density of Hatched Nests}

Our estimates of hatched nests/ha provide an integrated assessment of nest density and nest survival in different habitat settings. Across all 3 years, winter wheat produced at least half as many nests as perennial cover and almost 4 times as many nests as spring wheat (Table 3). However, our estimate for spring wheat is based on 1 year of data and our sample size is about half our average sample size for perennial cover and winter wheat. Although we suspect that our estimate for spring wheat would be similar with a larger sample size and across more years, our inference is limited because of the small sample size. We speculate that production of hatched nests might be lower in spring wheat because the sparse vegetation available in spring-planted crop fields does not attract many ducks. It is also thought that cultivation activities associated with spring-planted crop fields destroy a high proportion of the nests initiated. However, we found that in our study, $\leq 7 \%$ of the nests that failed in spring wheat were because of cultivation practices. The majority of the nests failed because of predation, which was comparable to winter wheat and perennial cover. Although our inference is limited because of sample size, our study provided some evidence that winter wheat is more productive than spring-seeded wheat. We encourage future studies to investigate duckling survival and possibly other components of fitness to determine if winter wheat offers additional advantages to spring-seeded crops.

\section{MANAGEMENT IMPLICATIONS}

In the face of declining CRP area and the push for farmers to convert more land to commodity crops, winter wheat offers a productive habitat alternative to wildlife managers who seek to balance the habitat needs of duck populations with the needs of modern agriculture. Planting winter wheat offers some agronomic advantages over spring-seeded crops. It allows the work load to be spread between the fall and spring and provides the advantage of having some fields already planted during wet spring conditions, when spring-seeding can be difficult. Winter wheat also offers economic benefits with a lower production cost and higher average yield than spring wheat (U.S. Department of Agriculture National Agricultural Statistics Service 2013). It prevents soil erosion over winter and competes well with weeds in the spring once it is established (Devries and Guyn 2013). We encourage wildlife managers to consider the benefits of winter wheat when designing and implementing programs to increase nesting habitat in crop-dominated landscapes.

\section{ACKNOWLEDGMENTS}

We are grateful for the logistical support from the staff at Ducks Unlimited, especially all of the agronomists who helped establish relationships with winter wheat producers. We are indebted to the many landowners who participated in this project-without their cooperation our project would not have been possible. Staff at the Northern Prairie Wildlife Research Center, especially C. M. Dovichin and M. A. Sovada provided logistical support and advice. The United States Fish and Wildlife Service Audubon National Wildlife Refuge provided housing and assistance during the floods of 2011, which we greatly appreciated. We thank N. A. Biasini, K. L. Kerfeld, J. S. McKnight, S. E. Woodward, and the many technicians whose tireless efforts and hard work made this project possible. Comments provided by the associate editor, Alan Leach, and 1 anonymous reviewer improved earlier versions of this manuscript. This project was funded by Bayer CropScience.

\section{LITERATURE CITED}

Ackerman, J. T. 2002. Of mice and mallards: positive indirect effects of coexisting prey on waterfowl nest success. Oikos 99:469-480.

Ackerman, J. T., A. L. Blackmer, and J. M. Eadie. 2004. Is predation on waterfowl nests density dependent?-Tests at three spatial scales. Oikos 107:128-140.

Afton, A. D. 1979. Time budget of breeding northern shovelers. Wilson Bulletin 91:42-49.

Arnold, T. W., L. M. Craig-Moore, L. M. Armstrong, D. W. Howerter, J. H. Devries, B. L. Joynt, R. B. Emery, and M. G. Anderson. 2007. Waterfowl use of dense nesting cover in the Canadian parklands. Journal of Wildlife Management 71:2542-2549.

Beauchamp, W. D., R. R. Koford, T. D. Nudds, R. G. Clark, and D. H. Johnson. 1996. Long-term declines in nest success of prairie ducks. Journal of Wildlife Management 60:247-257.

Benton, T. G., J. A. Vickery, and J. D. Wilson. 2003. Farmland biodiversity: is habitat heterogeneity the key? Trends in Ecology and Evolution 18:182-188.

Bishop, C. J., G. C. White, and P. M. Lukacs. 2008. Evaluating dependence among mule deer siblings in fetal and neonatal survival analyses. Journal of Wildlife Management 72:1085-1093.

Bloom, P. M., D. W. Howerter, R. B. Emery, and L. M. Armstrong. 2013. Relationships between grazing and waterfowl production in the Canadian prairies. Journal of Wildlife Management 77:534-544.

Burnham, K. P., and D. R. Anderson. 2002. Model selection and inference: a practical information theoretic approach. Spinger-Verlag, New York, New York, USA.

Caldwell, P. J., and G. W. Cornwell. 1975. Incubation behavior and temperatures of the mallard duck. Auk 92:706-731.

Cam, E., W. A. Link, E. G. Cooch, J. Monnat, and E. Danchin. 2002. Individual covariation in life-history traits: seeing the trees despite the forest. American Naturalist 159:96-105.

Claassen, R., F. Carriazo, J. C. Cooper, D. Hellerstein, and K. Ueda. 2011. Grassland to cropland conversion in the Northern Plains: the role of crop insurance, commodity, and disaster programs. U.S. Department of Agriculture, Economic Research Service ERR-120.

Cowan, W. F. 1982. Waterfowl production on zero tillage farms. Wildlife Society Bulletin 10:305-308.

Cowardin, L. M., D. S. Gilmer, and C. W. Shaiffer. 1985. Mallard recruitment in the agricultural environment of North Dakota. Wildlife Monographs 92:3-37.

Cowardin, L. M., T. L. Shaffer, and P. M. Arnold. 1995. Evaluation of duck habitat and estimation of duck population sizes with a remote-sensingbased system. National Biological Service Biological Science Report 2, Fort Collins, Colorado, USA.

Dahl, T. E. 1990. Wetlands losses in the United States 1780's to 1980's. U.S. Department of the Interior, Fish and Wildlife Service, Washington, D.C., USA.

Devries, J. H., and L. M. Armstrong. 2011. Impact of management treatments on waterfowl use of dense nesting cover in the Canadian Parklands. Journal of Wildlife Management 75:1340-1349.

Devries J. H., L. M. Armstrong, R. J. MacFarlane, L. Moats, and P. T. Thoroughgood. 2008. Waterfowl nesting in fall-seeded and spring-seeded cropland in Saskatchewan. Journal of Wildlife Management 72:17901797.

Devries, J. H., and K. L. Guyn. 2013. Winter wheat: agronomic and waterfowl benefits. Proceedings of the Ecology and Conservation of North 
American Waterfowl Symposium, 27-31 January 2013, Memphis, Tennessee, USA.

Dinsmore, S. J., G. C. White, and F. L. Knopf. 2002. Advanced techniques for modeling avian nest survival. Ecology 83:3476-3488.

Doherty, P. F., G. C. White, and K. P. Burnham. 2010. Comparison of model building and selection strategies. Journal of Ornithology 152:317-323.

Donovan, T. M., P. W. Jones, E. M. Annand, and F. R. Thompson III. 1997. Variation in local-scale edge effects: mechanisms and landscape context. Ecology 78:2064-2075.

Drever, M. C., T. D. Nudds, and R. G. Clark. 2007. Agricultural policy and nest success of prairie ducks in Canada and the United States. Avian Conservation and Ecology 2:5.

Duebbert, H. F., and H. A. Kantrud. 1987. Use of no-till winter wheat by nesting ducks in North Dakota. Journal of Soil and Water Conservation 42:50-53.

Flowerdew, J. R. 1997. Mammal biodiversity in agricultural habitats. Pages 25-40 in Proceedings of British Crop Protection Council Symposium on biodiversity and conservation in agriculture. British Crop Protection Council No. 69, Brighton, United Kingdom.

Forbes, M. R. L., R. G. Clark, P. J. Weatherhead, and T. Armstrong. 1994. Risk-taking by female ducks: intra- and interspecific tests of nest defense theory. Behavioral Ecology and Sociobiology 34:79-85.

Gehring, T. M., and R. K. Swihart. 2003. Body size, niche breadth, and ecologically scaled responses to habitat fragmentation: mammalian predators in an agricultural landscape. Biological Conservation 109:283-295.

Gloutney, M. L., R. G. Clark, A. D. Afton, and G. J. Huff. 1993. Timing of nest searches for upland nesting waterfowl. Journal of Wildlife Management 57:597-601.

Grant, T. A., and T. L. Shaffer. 2012. Time-specific patterns of nest survival for ducks and passerines breeding in North Dakota. Auk 129:319-328.

Grant, T. A., T. L. Shaffer, E. M. Madden, P. J. Pietz, and D. H. Johnson. 2005. Time-specific variation in passerine nest survival: new insights into old questions. Auk 122:661-672.

Greenwood, R. J., A. B. Sargeant, D. H. Johnson, L. M. Cowardin, and T. L. Shaffer. 1995. Factors associated with duck nest success in the prairie pothole region of Canada. Wildlife Monographs 128:3-57.

Greenwood, R. J., A. B. Sargeant, J. L. Piehl, D. A. Buhl, and B. A. Hanson. 1999. Foods and foraging of prairie striped skunks during the avian nesting season. Wildlife Society Bulletin 27:823-832.

Gunnarsson, G., and J. Elmberg. 2008. Density-dependent nest predationan experiment with simulated mallard nests in contrasting landscapes. Ibis 150:259-269.

Guyn, K. L., and R. G. Clark. 2000. Nesting effort of northern pintails in Alberta. Condor 102:619-628.

Heroldová, M., J. Bryja, J. Zejda, and E. Tkadlec. 2007. Structure and diversity of small mammal communities in agriculture landscape. Agriculture, Ecosystems and Environment 120:206-210.

Higgins, K. F. 1977. Duck nesting in intensively farmed areas of North Dakota. Journal of Wildlife Management 41:232-242.

Higgins, K. F., L. M. Kirsch, H. F. Duebbert, A. T. Klett, J. T. Lokemoen, H. W. Miller, and A. D. Kruse. 1977. Construction and operation of a cable-chain drag for nest searches. U.S. Fish and Wildlife Service Wildlife Leaflet 512, Washington, D.C., USA.

Hoekman, S. T., L. S. Mills, D. W. Howerter, J. H. Devries, and I. J. Ball. 2002. Sensitivity analyses of the life cycle of midcontinent mallards. Journal of Wildlife Management 66:883-900.

Howerter, D. W. 2003. Factors affecting duck nesting in the Aspen Parklands: a spatial analysis. Dissertation, Montana State University, Bozeman, USA.

Jimenez, J. E., M. R. Conover, R. D. Dueser, and T. A. Messmer. 2007. Influence of habitat patch characteristics on the success of upland duck nests. Human-Wildlife Conflicts 1:244-256.

Klett, A. T., H. F. Duebbert, C. A. Faanes, and K. F. Higgins. 1986. Techniques for studying nest success of ducks in upland habitats in the prairie pothole region. U.S. Fish and Wildlife Service Resource Publication 158, Washington, D.C., USA.

Klett, A. T., and D. H. Johnson. 1982. Variability in nest survival rates and implications to nesting studies. Auk 99:77-87.

Klett, A. T., T. L. Shaffer, and D. H. Johnson. 1988. Duck nest success in the prairie pothole region. Journal of Wildlife Management 52:431-440.
Koons, D. N., and J. J. Rotella. 2003. Comparative nesting success of sympatric lesser scaup and ring-necked ducks. Journal of Field Ornithology 74:222-229.

Krapu, G. L., R. J. Greenwood, C. P. Dwyer, K. M. Kraft, and L. M. Cowardin. 1997. Wetland use, settling patterns, and recruitment in mallards. Journal of Wildlife Management 61:736-746.

Kuehl, A. K., and W. R. Clark. 2002. Predator activity related to landscape features in northern Iowa. Journal of Wildlife Management 66:1224-1234.

Laake, J. L. 2013. RMark: an R Interface for analysis of capturerecapture data with MARK. Alaska Fisheries Science Center Report 2013-01. NOAA, National Marine Fisheries Service, Seattle, Washington, USA

Larivière, S., and F. Messier. 2000. Habitat selection and use of edges by striped skunks in the Canadian prairies. Canadian Journal of Zoology 78:366-372.

Lokemoen, J. T., and J. A. Beiser. 1997. Bird use and nesting in conventional, minimum-tillage, and organic cropland. Journal of Wildlife Management 61:644-655.

Mallory, M. L., and P. J. Weatherhead. 1993. Observer effects on common goldeneye nest defense. Condor 95:467-469.

Major, R. E., and C. E. Kendal. 1996. The contribution of artificial nest experiments to understanding avian reproductive success: a review of methods and conclusions. Ibis 138:298-307.

Milonski, M. 1958. The significance of farmland for waterfowl nesting and techniques for reducing losses due to agricultural practices. Transactions of the North American Wildlife Conference 23:215-228.

Padyšáková, E., M. Salek, L. Polednik, F. Sedlacek, and T. Albrecht. 2010. Predation on simulated duck nests in relation to nest density and landscape structure. Wildlife Research 37:597-603.

Péron, G., J. Walker, J. J. Rotella, J. E. Hines, and J. D. Nichols. 2014. Estimating nest abundance while accounting for time-to-event processes and imperfect detection. Ecology 95:2548-2557.

Phillips, M. L., W. R. Clark, S. M. Nusser, M. A. Sovada, and R. J. Greenwood. 2004. Analysis of predator movement in prairie landscapes with contrasting grassland composition. Journal of Mammalogy 85:187-195

Phillips, M. L., W. R. Clark, M. A. Sovada, D. J. Horn, R. R. Koford, and R. J. Greenwood. 2003. Predator selection of prairie landscape features and its relation to duck nest success. Journal of Wildlife Management 67:104-114.

Pieron, M. R., and F. C. Rohwer. 2010. Effects of large-scale predator reduction on nest success of upland nesting ducks. Journal of Wildlife Management 74:124-132.

Powell, L. A. 2007. Approximating variance of demographic parameters using the delta method: a reference for avian biologists. Condor 109:949-954.

R Development Core Team. 2013. R: a language and environment for statistical computing. R Foundation for Statistical Computing, Vienna, Austria.

Reynolds R. E., T. L. Shaffer, C. R. Loesch, and R. R. Cox Jr. 2006. The Farm Bill and duck production in the Prairie Pothole Region: increasing the benefits. Wildlife Society Bulletin 34:963-974.

Reynolds, R. E., T. L. Shaffer, R. W. Renner, W. E. Newton, and B. D. J. Batt. 2001. Impact of the Conservation Reserve Program on duck recruitment in the US Prairie Pothole Region. Journal of Wildlife Management 65:765-780.

Ringelman, K. M., J. M. Eadie, and J. T. Ackerman. 2012. Densitydependent nest predation in waterfowl: the relative importance of nest density versus nest dispersion. Oecologia 169:695-702.

Ringelman, K. M., and M. J. Stupaczuk. 2013. Dabbling ducks increase nest defense after partial clutch loss. Condor 115:290-297.

Robel, R. J., J. N. Briggs, A. D. Dayton, and L. C. Hulbert. 1970. Relationships between visual obstruction measurements and weight of grassland vegetation. Journal of Range Management 23:295-298.

Rotella, J. J., S. J. Dinsmore, and T. L. Shaffer. 2004. Modeling nest-survival data: a comparison of recently developed methods that can be implemented in MARK and SAS. Animal Biodiversity and Conservation 27:187-204.

Sargeant, A. B., S. H. Allen, and J. P. Fleskes. 1986. Commercial sunflowers: food for red foxes in North Dakota. Prairie Naturalist 18:91-94. 
Sargeant, A. B., R. J. Greenwood, M. A. Sovada, and T. L. Shaffer. 1993. Distribution and abundance of predators in the Prairie Pothole Region that affect duck production. U.S. Fish and Wildlife Service Resource Publication 194, Washington, D.C., USA.

Sargeant, A. B., and D. G. Raveling. 1992. Mortality during the breeding season. Pages 396-422 in B. D. J. Batt, A. D. Afton, M. G. Anderson, C. D. Ankney, D. H. Johnson, J. A. Kadlec, and G. L. Krapu, editors. The ecology and management of breeding waterfowl. University of Minnesota Press, Minneapolis, USA.

Saunders, D. A., R. J. Hobbs, and C. R. Margules. 1991. Biological consequences of ecosystem fragmentation review. Conservation Biology 5:18-32.

Sovada M. A., R. M. Anthony, and B. D. J. Batt. 2001. Predation on waterfowl in arctic tundra and prairie breeding areas: a review. Wildlife Society Bulletin 29:6-15.

Sovada, M. A., J. M. Roaldson, and A. B. Sargeant. 1999. Foods of American badgers in west-central Minnesota and southeastern North Dakota during the duck nesting season. American Midland Naturalist 142:410-414.

Sovada, M. A., M. C. Zicus, R. J. Greenwood, D. P. Rave, W. E. Newton, R. O. Woodward, and J. A. Beiser. 2000. Relationships of habitat patch size to predator community and survival of duck nests. Journal of Wildlife Management 64:820-831.

Stephens, S. E., J. J. Rotella, M. S. Lindberg, M. L. Taper, and J. K. Ringelman. 2005. Duck nest survival in the Missouri Coteau of North Dakota: landscape effects at multiple spatial scales. Ecological Applications 15:2137-2149.

Sturdivant, R. X., J. J. Rotella, and R. E. Russell. 2007. A smoothed residual based goodness-of-fit statistic for nest-survival models. Studies in Avian Biology 34:45.

Sugden, L. G., and G. W. Beyersbergen. 1986. Effect of density and concealment on American crow predation of simulated duck nests. Journal of Wildlife Management 50:9-14.

Sugden, L. G., and G. W. Beyersbergen. 1987. Effect of nesting cover density on American crow predation of simulated duck nests. Journal of Wildlife Management 51:481-485.
Thompson, S. C., and D. G. Raveling. 1987. Incubation behavior of emperor geese compared with other geese: interactions of predation, body size, and energetics. Auk 104:707-716.

Thompson S. J., T. W. Arnold, and S. Vacek. 2012. Impact of encroaching woody vegetation on nest success of upland nesting waterfowl. Journal of Wildlife Management 76:1635-1642.

U.S. Department of Agriculture Farm Service Agency. 2013. Conservation Reserve Program-Annual summary and enrollment statistics. U.S. Department of Agriculture, Washington, D.C., USA. http://www.fsa. usda.gov/Internet/FSA_File/summary12.pdf Accessed 10 Jan 2013.

U.S. Department of Agriculture National Agricultural Statistics Service [USDA NASS]. 2013. Agricultural statistics 2013. http://nass.usda.gov/ Publications/Ag_Statistics/2013/index.asp Accessed 10 Apr 2015.

U.S. Department of the Interior and Environment Canada. 1986. North American Waterfowl Management Plan. U.S. Department of the Interior and Environment Canada, Washington, D.C., USA.

van der Valk, A. 1989. Northern prairie wetlands. Iowa State University Press, Ames, USA.

Walker, J., Z. J. Cunningham, M. P. Vrtiska, S. E. Stephens, and L. A. Powell. 2008. Low reproductive success of mallards in a grasslanddominated landscape in the Sandhills of Nebraska. Prairie Naturalist 40:1-13.

Walker J., J. J. Rotella, and S. E. Stephens. 2013. Time-lagged variation in pond density and primary productivity affects duck nest survival in the Prairie Pothole Region. Ecological Applications 23:1061-1074.

Warren, J. M., J. Rotella, and J. E. Thompson. 2008. Contrasting effects of cattle grazing intensity on upland-nesting duck production at nest and field scales in the Aspen Parkland, Canada. Avian Conservation and Ecology 3:6.

Weller, M. W. 1956. A simple field candler for waterfowl eggs. Journal of Wildlife Management 20:111-113.

White, G. C., and K. P. Burnham. 1999. Program MARK: survival estimation from populations of marked animals. Bird Study 46 Supplement:120-138.

Associate Editor: Garth Herring. 